\title{
A Comparative Study on the Spatial Structure of Urban Agglomeration in the Middle Reaches of the Yangtze River Based on Fractal Theory
}

\author{
LIU Chun ${ }^{1,2, a, ~ * ~}$ \\ 1 Wuhan Technology and Business University, Department of Management, Wuhan 430065, China \\ 2 Hubei Business Service Development Research Center, Wuhan 430065, China \\ a lc576@126.com
}

\begin{abstract}
With the comprehensive economic strength of the urban agglomeration in the middle reaches of the Yangtze River, the more closely the economic linkage between urban system within urban agglomeration, the higher demand on spatial structure of urban system. This paper comparatively analyses spatial aggregation dimension and spatial correlation dimension of 56 cities of Wuhan urban agglomeration, Changzhutan urban agglomeration, Poyang Lake urban agglomeration in the urban agglomeration in the middle reaches of the Yangtze River by the fractal method, achieves 4 conclusions: (1) 3 urban agglomerations in the middle reaches of the Yangtze River have the spatial fractal character; (2) Crow fractal dimension of Wuhan urban agglomeration is the highest, Changzhutan urban agglomeration the lowest, the spatial distribution of urban system is relatively concentrated; (3) The spatial structure of the three urban agglomerations presents the characteristics of axis, cities distribution along the high-speed channel; (4) Traffic network accessibility of urban system of the three urban agglomerations is good, Traffic network accessibility of Poyang Lake urban agglomeration is the best in the urban agglomeration in the middle reaches of the Yangtze River, that of Wuhan urban agglomeration is the worst.
\end{abstract}

Key words: Urban agglomeration in the middle reaches of the Yangtze River; urban system; Fractal; Spatial Structure

\section{Introduction}

In August 2012, the State Council of the PRC promulgated the " guidelines on vigorously implement the strategy of spurring the rise of the central region ", referred to "the cooperation, the integrated development of the three city groups of urban agglomeration in the middle reaches of the Yangtze River including Wuhan urban agglomeration, Changzhutan urban agglomeration and Poyang Lake urban agglomeration" [1] ; In March 2014, the State Council of the PRC issued the " national new urbanization plan (2014-2020) ", to accelerate the development of Cheng-Yu Economic Zone, urban agglomeration in the middle reaches of the Yangtze River, Central Plains Economic Region and Harbin-Changchun urban agglomeration, and to become an important growth pole to promote land spatial balanced development and lead the regional economic development ${ }^{[2]}$; In April 2015, the State Council approved " Development planning of urban agglomeration in the middle reaches of the Yangtze River ", pointed out that urban agglomeration in the middle reaches of the Yangtze River will be built as an important support for the Yangtze River economic belt, a new 
growth pole of the national economy and urban agglomeration with a certain international influence by new paths and new models of cooperative development ${ }^{[3]}$. Urban agglomeration in the middle reaches of the Yangtze River is officially positioned as a new growth pole of Chinese economic development, the new urbanization pilot area of the Central and Western China, in this context, it is of great significance to construct a reasonable urban system level, function and spatial structure of the urban agglomeration in the middle reaches of the Yangtze River.

There are many literatures on urban system and spatial structure of Urban Agglomeration, ZENG Ju-xin(2009) ${ }^{[4]}$ analyzes the dynamic mechanism to promote the spatial structure change of villages and towns, and studies the coupling mechanism of each dynamic mechanism. ZHANG Chao(2015) ${ }^{[5]}$ uses the analytical methods including city rank-size Rule, spatial autocorrelation analysis and the weighted standard deviation ellipse, with the DMSP/OLS night time light data, systematically to analyze the spatial structure and changing features of the city system in the Yangtze economy belt, the city system in the area has a core-peripheral structure, relatively dense in the east and sparse in the middle and the west. LI Jian-xin(2015) ${ }^{[6]}$ analyses the features of the spatial structure of prefecture-level and above cities in Central China by factor analysis and Kernel density, spatial distribution of urban system in central China belongs to the cluster pattern. HUANG Yan-ni (2016) ${ }^{[7]}$ uses the Pareto index, Mono index and Primate City to study the evolution characteristics and inherent law of spatial structure of the 10 representative urban agglomerations in China, the average Primate City of 10 urban agglomerations gradually increases from east to west, the spatial distribution of urban agglomeration in the eastern part is relatively balanced compared with that of the western. SUN Tie-shan (2016) ${ }^{[8]}$ applies Location coefficient, Polycentric index, Granger causality tests to analyze the evolution of economic agglomeration and its spatial structure in the Yangtze River delta region, the Pearl River delta region, and the Beijing-Tianjin-Hebei region, and examine the relationship between economic agglomeration, changing spatial structure and regional economic growth. The change trends of the agglomeration of economic activities in these three major metropolitan regions over time with economic growth provide the evidence to support the inverse U curve hypothesis of Williamson.

In addition, Fang Da-chun (2013) ${ }^{[9]}$ and Huang Qian (2014) ${ }^{[10]}$ uses the fractal geometry theory to respectively calculate the traffic space aggregation dimension and spatial correlation dimension in the Yangtze River Delta city group and Pingdingshan urban system; Bai Yong-liang (2014) ${ }^{[11]}$, He Huan-huan (2014) $)^{[12]}$, Xiao Ru-qin(2014) $)^{[13]}$ and Wang Lei(2014) ${ }^{[14]}$ measure the economic connection between different cities in urban agglomeration in the middle reaches of the Yangtze River, Changzhutan urban agglomeration, Shandong Peninsula Blue Economic Zone by gravity model and the intensity of urban flow model; Wang Sheng-yun $\left(2013^{[15]}\right.$, $2015^{[16]}$ ) applies social network analysis method to respectively explore the spatial linkage and network structure's characteristics of urban agglomerations in the middle reaches of Yangtze River and the Yangtze River Economic Zone; Liu Yao-bin 
(2013) $)^{[17]}$ and Liu Hui(2013) $)^{[18]}$ analyzes network structure of urban agglomeration in Beijing-Tianjin-Hebei metropolitan region and around the Poyang Lake on the basis of the social network analysis and urban gravity model. Liu Jing-yu (2014) ${ }^{[19]}$ and Yao Zuo-lin (2017) ${ }^{[20]}$ uses the econometric models of urban centrality, economic contact intensity model to study the spatial pattern feature of Cheng-Yu Economic Zone urban agglomeration and Central Plains Economic Region urban groups. At present, the research on the urban spatial structure has not formed a set of solid research paradigm, the research on object region, scale, time series and theoretical methods is different, the conclusions are not the same.

This paper takes 16 cities of Wuhan urban agglomeration, 22 cities of Changzhutan urban agglomeration, and 18 cities of Poyang Lake urban agglomeration in urban agglomeration in the middle reaches of the Yangtze River as the research object, and uses the fractal geometry theory to respectively measure the traffic spatial aggregation dimension and spatial correlation dimension of urban systems in Wuhan urban agglomeration, Changzhutan urban agglomeration and Poyang Lake urban agglomeration. Based on the analysis of the aggregation dimension, comparatively study the correlation dimension and network accessibility of spatial structure of urban system in three urban agglomerations, and reveals the characteristics of the spatial structure of the three urban agglomerations, finally puts forward the suggestions of the spatial distribution optimization in urban agglomeration in the middle reaches of the Yangtze River.

2. Fractal research method of urban system spatial structure of urban agglomeration

\subsection{Aggregation dimension measurement}

Assume that the distribution of city system elements around the central city of urban agglomeration in accordance with some self-similar rules (usually the primacy city in the system) performs condensed state, and the fractal body is uniformly distributed, then we can determine the relationship between the circle of $r$ radius in the town of "particles" $N(\mathrm{r})$ and the corresponding radius by means of geometric measure method, i.e. there:

$$
N(\mathrm{r}) \propto r^{D f}
$$

(1) formula: $D f$ for fractal dimension. It is shown that if the assumption is correct, the radius of gyration method can be used to calculate the fractal dimension of spatial agglomeration of urban system. It has been proved that the above assumptions are valid. Taking into account that the unit value of the radius $r$ affects the value of the fractal dimension, it can be transformed into an average radius, average radius formula for:

$$
R_{s}=\sqrt{\sum_{i=1}^{s} \frac{r_{i}^{2}}{S}}
$$

Then there will be fractal dimension: 


$$
R_{s} \propto S^{\frac{1}{D}}
$$

Formula (2) and (3) $: R_{s}$ is the average radius of the urban system; $r_{i}$ is euclidean distance ( or called gravity distance ) between city $i$ and the measure center city; $S$ is the number of cities; $D$ is the spatial fractal dimension of urban agglomeration, $D$ reflects the characteristics of urban spatial random aggregation around the central city in urban agglomeration, namely the urban distribution density change from the measure center city to periphery. Generally speaking, when the agglomeration dimension $D$ is less than 2, the urban distribution density of urban agglomeration gradually decline from the central city to periphery, known as aggregated distribution. When the agglomeration dimension $D$ is equal to 2, the urban distribution of urban agglomeration uniformly varying from the central city to periphery. when the agglomeration dimension greater than 2, the urban distribution density of urban agglomeration gradually increasing from the central city to periphery, this is an abnormal situation.

\section{2 correlation dimension measurement}

It is assumed that there are $N$ cities in the urban agglomeration, and the spatial correlation functions between these cities can be expressed as:

$$
C(r)=\frac{1}{N^{2}} \sum_{i}^{N} \sum_{j}^{N} H\left(r-d_{i j}\right) \quad(i \neq j)
$$

(4) formula: $r$ is yardstick; $d_{i j}$ is the crow distance ( or cow distance ) between crows for city $i$ and city $j ; H\left(r-d_{i j}\right)$ is Heaviside function, as follows:

$$
H\left(r-d_{i j}\right)=\left\{\begin{array}{ll}
1, & \left(d_{i j} \leq r\right) \\
0, & \left(d_{i j}>r\right)
\end{array} \quad(i \neq j)\right.
$$

If the spatial distribution of urban system is fractal, it should have scaling invariability, expression as follows:

$$
C(\mathrm{r}) \propto r^{D}
$$

(6) formula: $D$ is fractal dimension, called spatial correlation dimension, which reflects the relevance and accessibility of traffic network between urban system.

In general, the correlation dimension $D$ vary range from 1 to 2 . When the correlation dimension $D$ is close to 1 , the urban system distribution have a tendency to concentrate to a geographical line, such as railway, highway, mountains, rivers, coastal etc. When the smaller the correlation dimension $D$, the more concentrated the urban system spatial distribution, the stronger the interaction between urban system. On the contrary, when the larger the correlation dimension $D$, the uniformer the urban system spatial distribution, the weaker the interaction between urban system.

The unique application of spatial correlation dimension indicates the relevance between urban system by network accessibility degree. The definition of network accessibility degree is as follows: 


$$
\rho=\frac{D^{\prime}}{D}
$$

(7) formula: $D^{\prime}$ is cow dimension, namely, the fractal dimension obtained from $d_{i j}$ instead of the traffic distance. $D$ is crow dimension, namely, the fractal dimension obtained from $d_{i j}$ instead of the euclidean distance. $\rho$ is the ratio of cow dimension to crow dimension, which reflects network accessibility degree between urban system in urban agglomeration. The more close to $1 \rho$ value, the better the traffic network accessibility between urban system, the higher the correlation degree between urban system. When $\rho$ is less than 0.5 , the traffic network connectivity between urban system is poor. When $\rho$ is less than 1 , and greater than 0.5 , the traffic network connectivity between urban system is good. When $\rho$ is equal to 1 , the traffic network connectivity between urban system reach the limit of the best .

3. An empirical study on the spatial structure fractal of the three urban agglomerations in the middle reaches of the Yangtze River

\subsection{Sources of date}

In this paper, the traffic distances ( unit: $\mathrm{km}$ ) between the urban system in the urban agglomerations are collated according to the shortest highway distance between the urban system in Baidu maps; The straight-line distances ( unit: $\mathrm{km}$ ) between the urban system are obtained through the calculation of the latitude and longitude of urban system.

3.2 The fractal dimension measurement of spatial structure of three urban agglomerations in the middle reaches of the Yangtze River

Wuhan, Changsha, Nanchang respectively as the measure center of Wuhan urban agglomeration, Changzhutan urban agglomeration and Poyang Lake urban agglomeration, respectively calculate the gravity distance $\left(r_{\mathrm{i}}\right)$ between each city in urban agglomeration and the measure center city, and converted the gravity distance to the average radius of $R$ s ( Table 1 ), then double logarithmic plots ( Figure 1 ) are drawn by the values of the dot ( $S, R s$ ). By means of least square method, we can measure the aggregation dimension $D$ of the spatial structure of the urban system of the three urban agglomerations in the middle reaches of the Yangtze River.

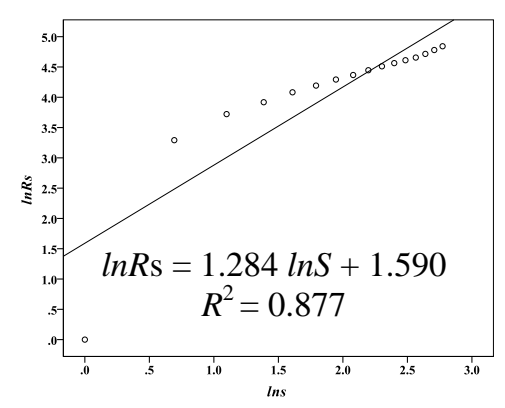

A. Wuhan urban agglomeration

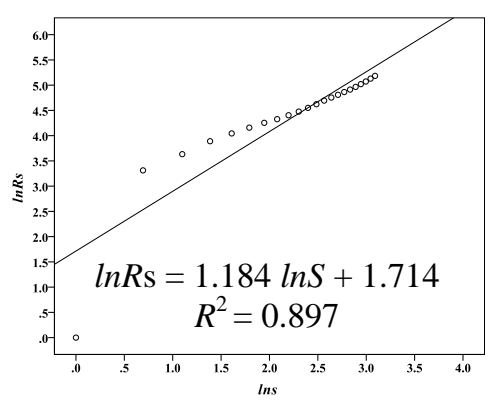

B.Changzhutan urban agglomeration

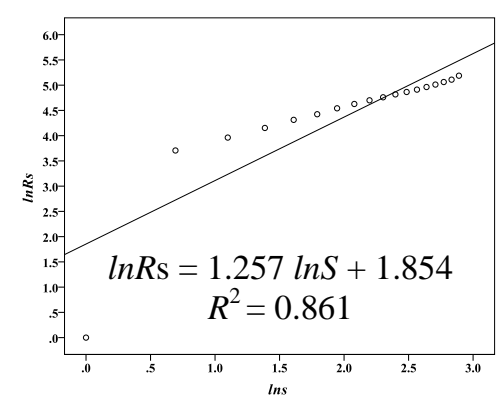

C.Poyang Lake urban agglomeration

Fig.1 spatial structure dimension of urban system in 3 urban agglomerations 
Tab.1 The fractal dimension of the spatial structure of the urban agglomerations in the middle reaches of the Yangtze River based on provincial capital city as the center of measurement

\begin{tabular}{lcccc}
\hline Urban agglomeration & $\begin{array}{c}\text { Measurement } \\
\text { Center }\end{array}$ & $\begin{array}{c}\text { Logarithmic regression } \\
\text { equation }\end{array}$ & $\begin{array}{c}\text { Fractal } \\
\text { dimension (D) }\end{array}$ & $\begin{array}{c}\text { Determination } \\
\text { coefficient }\left(R^{2}\right)\end{array}$ \\
\hline $\begin{array}{l}\text { Wuhan urban } \\
\text { agglomeration }\end{array}$ & Wuhan & $\ln R \mathrm{~s}=1.284 \ln S+1.590$ & 1.284 & 0.877 \\
$\begin{array}{l}\text { Changzhutan urban } \\
\text { agglomeration }\end{array}$ & Changsha & $\ln R \mathrm{~s}=1.184 \ln S+1.714$ & 1.184 & 0.897 \\
$\begin{array}{l}\text { Poyang Lake urban } \\
\text { agglomeration }\end{array}$ & Nanchang & $\ln R \mathrm{~s}=1.257 \ln S+1.854$ & 1.257 & 0.861 \\
\hline
\end{tabular}

As shown in Figure 1 (A, B, C) for $\ln S-\ln R s$ double logarithmic plots. Although Wuhan, Changsha, Nanchang respectively as the measure center of Wuhan urban agglomeration, Changzhutan urban agglomeration and Poyang Lake urban agglomeration are the center of geometry, their double logarithmic coordinates are not linear distribution, but the three time curve plots, appear multi-fractal characteristics, and tend to quasi fractal.

From the fractal dimension of the spatial structure of the three urban agglomerations based on provincial capital city as the center of measurement ( Table 1 ), spatial random aggregation dimensions of Wuhan urban agglomeration, Changzhutan urban agglomeration and Poyang Lake urban agglomeration are respectively 1.284, 1.184 and 1.257, aggregation dimension is greater than 1 , the coefficient of determination is less than 0.9. The above shows that the urban distribution density extending from the provincial capital city to periphery in the three urban agglomerations rapidly decline, the spatial distribution is not uniform, and the central attraction is weak, which indicates that the three urban agglomerations have many small cluster centers from the geographical spatial distribution.

3.3 Calculation of correlation dimension of spatial structure of the three cities of the middle reaches of the Yangtze River

According to the distance between urban system of three urban agglomerations, this paper determines yardstick $\Delta r=15 \mathrm{~km}$, then the distance points $C(r)$ between the urban system of within the distance $r$ of both in urban agglomeration will change with the change of $r$. In this way, we can get the dot matrix $[r, C(r)]$ according to the distance of the crow and the cow. By the use of SPSS software, the dot matrix $[r, C$

$(r)$ ] is converted into the corresponding double logarithmic matrix, and on the basis of the above, draws the double logarithmic matrix into coordinate plot.

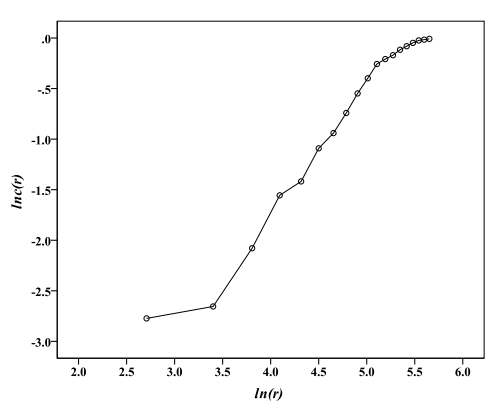

A. Wuhan urban agglomeration

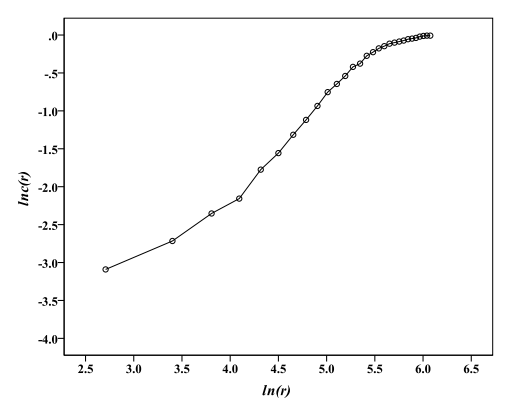

B. Changzhutan urban agglomeration

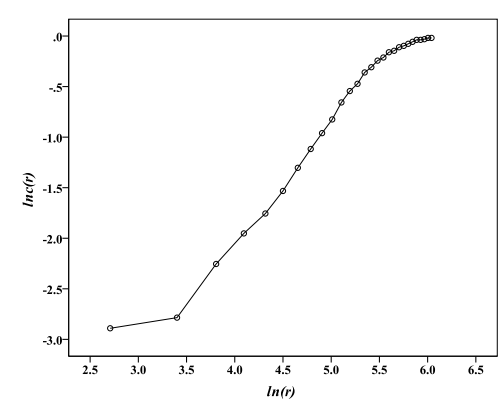

C. Poyang Lake urban agglomeration

Fig. 2 double logarithmic plot of correlation dimension of crow distance 


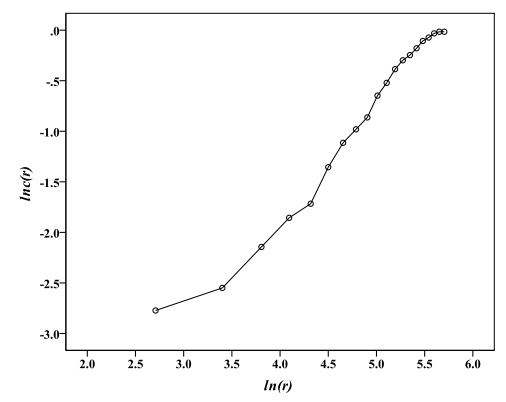

A. Wuhan urban agglomeration

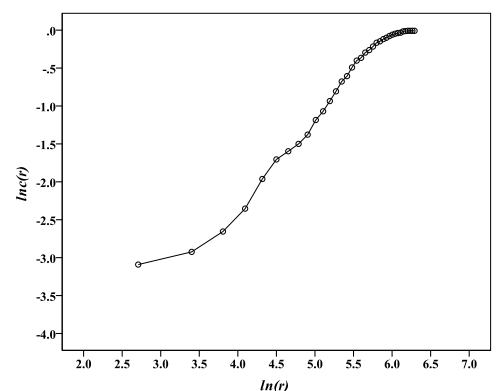

B. Changzhutan urban agglomeration

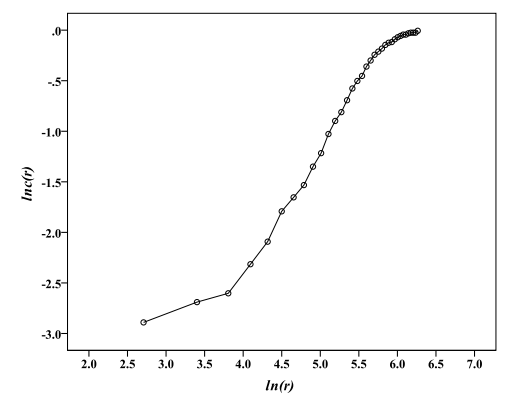

C. Poyang Lake urban agglomeration

Fig.3 double logarithmic plot of correlation dimension of cow distance

As shown in Figure 2 (A, B, C), Figure 3 (A, B, C) for double logarithmic plots of correlation dimension of crow distance and cow distance in Wuhan urban agglomeration, Changzhutan urban agglomeration and Poyang Lake urban agglomeration. The linear regression is performed by using the double logarithmic values of the points, to calculate the crow correlation dimension $D$ and cow correlation dimension $D^{\prime}$ of urban system in the urban agglomeration, and further calculate the ratio of cow dimension to crow dimension of urban system spatial structure in three urban agglomerations ( Table 2 ).

Tab.2 The ratio of cow dimension to crow dimension of urban system spatial structure in three urban agglomerations

\begin{tabular}{lllcc}
\hline Urban agglomeration & $\begin{array}{c}\text { Logarithmic regression } \\
\text { equation }\end{array}$ & $\begin{array}{c}\text { Fractal dimension } \\
\text { value }\end{array}$ & $\begin{array}{c}\text { Determination } \\
\text { coefficient }\left(R^{2}\right)\end{array}$ & $\begin{array}{c}\text { The ratio of cow } \\
\text { dimension to crow } \\
\text { dimension }(\rho)\end{array}$ \\
\hline Wuhan urban & $\ln C(r)=1.103 \ln r-6.068$ & $D^{\prime}=1.103$ & 0.972 & 0.9791 \\
agglomeration & $\ln C^{\prime}(r)=1.080 \ln r-6.105$ & $D=1.080$ & 0.974 & 0.9877 \\
Changzhutan urban & $\ln C(r)=1.053 \ln r-6.168$ & $D^{\prime}=1.053$ & 0.971 & \\
agglomeration & $\ln C^{\prime}(r)=1.040 \ln r-6.342$ & $D=1.040$ & 0.974 & 0.9883 \\
Poyang Lake urban & $\ln C(r)=1.022 \ln r-5.993$ & $D^{\prime}=1.022$ & 0.974 & 0.965 \\
agglomeration & $\ln C^{\prime}(r)=1.010 \ln r-6.170$ & $D=1.010$ & 0.963 & \\
\hline
\end{tabular}

Based on the calculation of the spatial correlation dimension of crow distance and traffic correlation dimension of cow distance, the ratio of cow dimension to crow dimension of the three urban agglomerations are obtained: Wuhan urban agglomeration $\rho=0.9791$, Changzhutan urban agglomeration $\rho=0.9877$, Poyang Lake urban agglomeration $\rho=0.9883$. Determination coefficients of crow dimension and cow dimension logarithmic regression equation are close to 1 , so the goodness of fit is better.

\section{Fractal analysis of spatial structure of three urban agglomerations}

It is calculated of crow correlation dimension, cow correlation dimension and both dimension ratio for city system spatial structure in Wuhan urban agglomeration, Changzhutan urban agglomeration and Poyang Lake urban agglomeration. The spatial structure of 3 urban agglomerations has the following characteristics: 
4.1 The spatial structure of the three urban agglomerations has fractal characteristics

It is calculated of spatial fractal dimension for Wuhan urban agglomeration, Changzhutan urban agglomeration and Poyang Lake urban agglomeration respectively based on Wuhan, Nanchang, Changsha as the center of measurement. The research results show that the three urban agglomerations have multi-fractal characteristics, and tend to quasi fractal features, The three urban agglomerations have many small cluster centers from the geographical spatial distribution.

4.2 Spatial structure characteristics of crow distance and cow distance

The spatial correlation values of cow dimension and crow dimension of Wuhan urban agglomeration, Changzhutan urban agglomeration, Poyang Lake urban agglomeration are greater than 1 , and the goodness of fit is better.

The crow spatial correlation dimension of city system in 3 urban agglomerations reflects the spatial distribution of urban system is relatively concentrated, 3 urban agglomerations is sorted by the correlative intensity between city system: Wuhan urban agglomeration > Poyang Lake urban agglomeration > ChangZhutan urban agglomeration.

The cow spatial correlation dimension of city system in 3 urban agglomerations shows the spatial structure of the three urban agglomerations presents the characteristics of axis, the main cities in Wuhan urban agglomeration spread along the Beijing-Guangzhou Railway and Shanghai-Chengdu Expressway, those in ChangZhutan urban agglomeration spread along the Beijing-Guangzhou Railway, and those in Poyang Lake urban agglomeration spread along the Beijing-Kowloon Railway axis. The 3 urban agglomerations should vigorously develop Intercity Express Railway based on the existing traffic.

4.3 The spatial structure characteristics of the ratio of cow dimension to crow dimension of three urban agglomerations

The ratio of cow dimension to crow dimension of Wuhan urban agglomeration, Changzhutan urban agglomeration, Poyang Lake urban agglomeration was respectively $0.9791,0.9877$ and 0.9883 , close to 1 . The above shows that the traffic accessibility of city system in 3 urban agglomerations is very good, and the traffic network development is relatively good. At the same time the numerical size of the ratio of cow dimension to crow dimension reflects the difference of traffic network accessibility of city system in 3 urban agglomerations, 3 urban agglomerations is sorted by the rank of traffic network accessibility: Poyang Lake urban agglomeration $>$ ChangZhutan urban agglomeration $>$ Wuhan urban agglomeration.

\section{Conclusion}

This paper comparatively analyses spatial structure characteristics of 56 cities of Wuhan urban agglomeration, Changzhutan urban agglomeration, Poyang Lake urban agglomeration in the urban agglomeration in the middle reaches of the Yangtze River, the results show that the spatial structure of urban system in 3 urban agglomerations have fractal character, the spatial distribution of urban system elements is relatively 
concentrated, and present the axis distribution, Traffic network accessibility of urban system of the three urban agglomerations is good, but there are differences in the intensity of the correlation and the accessibility of traffic network between urban system. It is necessary to further plan intercity high-speed transport system of urban agglomeration based on the existing traffic advantages.

\section{Acknowledgment}

This work was financially supported by Humanities and social Scientific Research Guidance Project for Hubei Provincial Department of Education (16G149) fund.

Corresponding author: LIU Chun, Wuhan Technology and Business University, Department of Management, Wuhan 430065, CHINA

\section{References}

[1] State Council of the PRC. Some opinions on vigorously implementing the strategy of promoting the rise of the central region [EB/OL]. http://www.gov.cn/zwgk/2012-08/31/content_2214579.htm, 2012-08-31/2017-03-12.

[2] State Council of the PRC. National new urbanization plan (2014-2020) [EB/OL]. http://www.gov.cn/gongbao/content/2014/content_2644805.htm, 2014-03-14/2017-03-12.

[3] National Development and Reform Commission of the PRC. Development planning of urban agglomeration in the middle reaches of the Yangtze River [EB/OL]. http://www.sdpc.gov.cn/zcfb/zcfbtz/201504/t20150416_688229.html, 2015-04-13/2017-03-12.

[4] ZENG Ju-xin, JIANG Zi-long, TANG Li-ping. Study on the dynamic mechanism of the spatial structure change of Chinese villages and towns [J]. Study and Practice,2009,(12):49-54.

[5] ZHANG Chao,WANG Chunyang,LV Yongqiang,etc. Research on City System Spatial Structure of the Yangtze River Economic Belt: Based on DMSP/OLS Night Time Light Data[J]. Urban Development Studies, 2015, 22(3): 19-27.

[6] LI Jianxin, ZHONG Yexi, XU Yu. Study on the spatial structure of urban system in Central China [J]. World Regional Studies, 2015, 24(2) : 78-87.

[7] HUANG Yanni, GAO Bo, WEI Shouhua. Spatial distribution and evolution of urban agglomerations in China[J]. Economist, 2016(9): 50-58.

[8] SUN Tie-shan. Evolution of Agglomeration and Its Spatial Structure with Economic Growth in Three Major Metropolitan Regions of China[J]. Economic Geography, 2016, 36(5): 63-70.

[9] FANG Da-chun,YANG Yi-wu. Study on Transportation Spatial Structure Fractal Characteristics of Yangtze River Delta City Group in High-speed Rail Era [J]. Areal Research and Development, 2013, 32(2): 52-56.

[10] HUANG Qian,LI Hui-jie,SUN Hai-ling. Fractal Analysis of Pingdingshan Urban System Spatial Structure Based on GIS Technology [J]. Natural Science Journal of Xiangtan University, 2014, 36(4): 95-99.

[11] DANG Yan-long, BAI Yong-liang. Research on Spatial Mechanism and Structure of Urban Agglomeration in the Middle Reaches of the Yangtze River [J]. Study of Macroeconomic, 2014, (11): 47-58,95.

[12] HE Huan-huan, Lv Bin. The Measurement on Economic Connection in Changzhutan Urban Agglomeration [J]. Economic Geography, 2014, 34(7): 67-74. 
[13] XIAO Ru-qin, CHEN Dong-jing. The Spatial Contacts among Cities of the Shandong Peninsula Blue Economic Zone [J]. Economic Geography, 2014, 34(8): 75-80.

[14] WANG Lei, WU Ye. Study on economic relations of urban agglomeration in the middle reaches of the Yangtze River Based on urban flow [J]. Jianghuai Tribune, 2014(3): 62-69.

[15] WANG Sheng-yun, QIN Zun-wen, DAI Lu, etc. Spatial Economic Connection and Network Structure of Urban Agglomerations in the Middle Reaches of the Yangtze River: by Using the Methods of Transportation Cost and Network Analysis [J]. Economic Geography, 2013, 33(4): 64-69.

[16] WANG Sheng-yun, ZHAI Chen-yang. The Network Structure and Space Cooperation Path of Urban Agglomerations in the Yangtze River Economic Zone [J]. Economic Geography, 2015, 35(11): 61-70.

[17] LIU Yao-bin, DAI Lu. Economic Contact Analysis with Network Structure of Urban Agglomeration around the Poyang Lake Based on SNA [J]. Resources and Environment in the Yangtze Basin, 2013, 22(3):263-271.

[18] LIU Hui, SHEN Yu-ming, MENG Dan, etc. The City Network Centrality and Spatial Structure in the Beijing-Tianjin-Hebei Metropolitan Region [J]. Economic Geography, 2013, 33(8): 37-45.

[19] LIU Jing-yu, DING Zhi-wei, SUN Fang, etc. Reconstruction of Urban Spatial Structure in Central Plains Economic Region [J]. Economic Geography, 2014, 34(10): 53-61.

[20] YAO Zuolin, TU Jianjun, NIU Huimin, etc. The Research on Urban Agglomeration Spatial Structure of Cheng-Yu Economic Zone[J]. Economic Geography, 2017, 37(1): 82-89. 